\title{
Chapter 12 \\ Public Education and Outreach \\ Opportunities for Crop Wild Relatives in North America
}

\author{
Tara Moreau and Ari Novy
}

\begin{abstract}
Successful programs of crop wild relative (CWR) exploration, conservation, and utilization are ultimately dependent on sustained public prioritization and support, which in turn requires public awareness and engagement. Here we discuss the importance of advancing North America public education and outreach activities related to CWR, including improving capacity for public engagement, stakeholder building, partnering for education and outreach, and programmatic development. We focus specifically on the potential of botanic gardens as excellent partners for public engagement on CWR due to their presence in major population centers, knowledge of informal educational practices, and familiarity with plant biodiversity and agricultural crop species. We also discuss CWR outreach efforts outside of North America as well as related environmental education efforts within the region. This chapter provides an informal education and outreach primer for researchers who want to incorporate public engagement into their CWR research programs, as well as for informal education professionals seeking to capitalize on the growing public interest in food systems to explore food-related biodiversity topics.
\end{abstract}

Keywords Agricultural education · Broader impacts · Capacity building · Informal education · Germplasm education · Botanical Gardens

\footnotetext{
T. Moreau $(\bowtie)$

University of British Colombia Botanical Garden, Vancouver, BC, Canada

e-mail: tara.moreau@ubc.ca
}

\author{
A. Novy \\ Leichtag Foundation, Encinitas, CA, USA \\ National Museum of Natural History, Smithsonian Institution, Washington, DC, USA \\ University of California-San Diego, San Diego, CA, USA \\ San Diego Botanic Garden, Encinitas, CA, USA \\ e-mail: anovy@sdbgarden.org
}

S. L. Greene et al. (eds.), North American Crop Wild Relatives, Volume 1, https://doi.org/10.1007/978-3-319-95101-0_12 


\subsection{Introduction}

In the face of a changing climate, prioritizing the exploration, conservation, and utilization of crop wild relatives (CWR), and food plant genetic resources in general, is vital for future food security. As the ancestors and relatives of our food plants, CWR are important sources of genetic diversity because they have adapted to survive in many different soil, pest, disease, and growing conditions. They have tremendous breeding value for food plant productivity, nutrition, and sustainability. However, the planet's sixth mass extinction of species is underway and one in five plant species threatened (Ceballos et al. 2015; Royal Botanic Gardens Kew 2016). Currently, CWR are underrepresented in genebanks and threated in their native habitats (Castañeda-Álvarez et al. 2016; Hunter and Heywood 2011).

Agricultural scientists dedicated to the exploration, conservation, and use of CWR can increase the impact of their work through collaborations with public education and outreach communities. Public engagement and education are key deliverables in international conservation frameworks (e.g., Global Strategy for Plant Conservation and UN Sustainable Development Goals) (Convention on Biological Diversity 2012; United Nations 2017). At local levels, public engagement can raise the profile of CWR as part of broader agendas on biodiversity conservation, agricultural development, and rural economy revitalization.

Despite considerable experience that agricultural scientists generally have with academic research and postsecondary teaching, very few research professionals have formal training or practice in public education and outreach (Varner 2014). Yet, the success of public sector research has been linked to efficacy of public engagement (Boyer 1996), to the point where an increasing number of funding agencies require public outreach as a component of research projects (Andrews et al. 2005). As such, large-scale research efforts, and certainly any of those that are publicly funded, should include dedicated efforts to integrate public education and outreach.

Building capacity through education is essential to increasing environmentally responsible collective action (Amel et al. 2017). The topic of CWR connects important communities involved with biodiversity conservation, agriculture, and food security and as such offers many topics and curricula of potential interest to the general public. There is much to be learned from pre-existing food and agriculture literacy programs and the significant networks of individuals and organizations that can support agricultural scientists in their CWR research efforts.

This chapter focuses on the value of public education and outreach related to CWR efforts. Here, informal education is defined as any educational engagement that is not a part of formal education (i.e., not a part of k-12 or postsecondary education). Informal education compliments formal education. For example, a weekend visit to a local botanic garden can reinforce a student's recent classroom studies of habitat and food webs. Benefits and advantages of informal education include 
engagement of a wide audience, freedom from the formality of classroom education, the potential to engage key stakeholders such as civic leaders, and the ability to highlight subject areas, such as CWR, which are not typically covered in formal education curricula. A suite of CWR-related topics are appropriate for public education, such as the origins of domesticated plants, the value of crop relatives to agriculture, practical benefits of plant conservation, genebank conservation, plant breeding, and the utilization of genetic resources. These topics connect to a diversity of wider educational subjects including agriculture, plant conservation, food plant genetics, ethnobotany, geography, history, planning, sustainable development, and more. In practice, educational opportunities related to CWR are endless.

The goal of this chapter is to explore approaches to build CWR capacity through public education, highlight previous CWR educational programs, and identify potential stakeholders and allies for agricultural scientists working with CWR. Botanic gardens are given particular emphasis as important nodes for CWR research, outreach, and collaboration because of their strong levels of engagement with the CWR community, expertise at presenting plant science topics to the public, and their proximity to population centers in North America (Fig. 12.1).

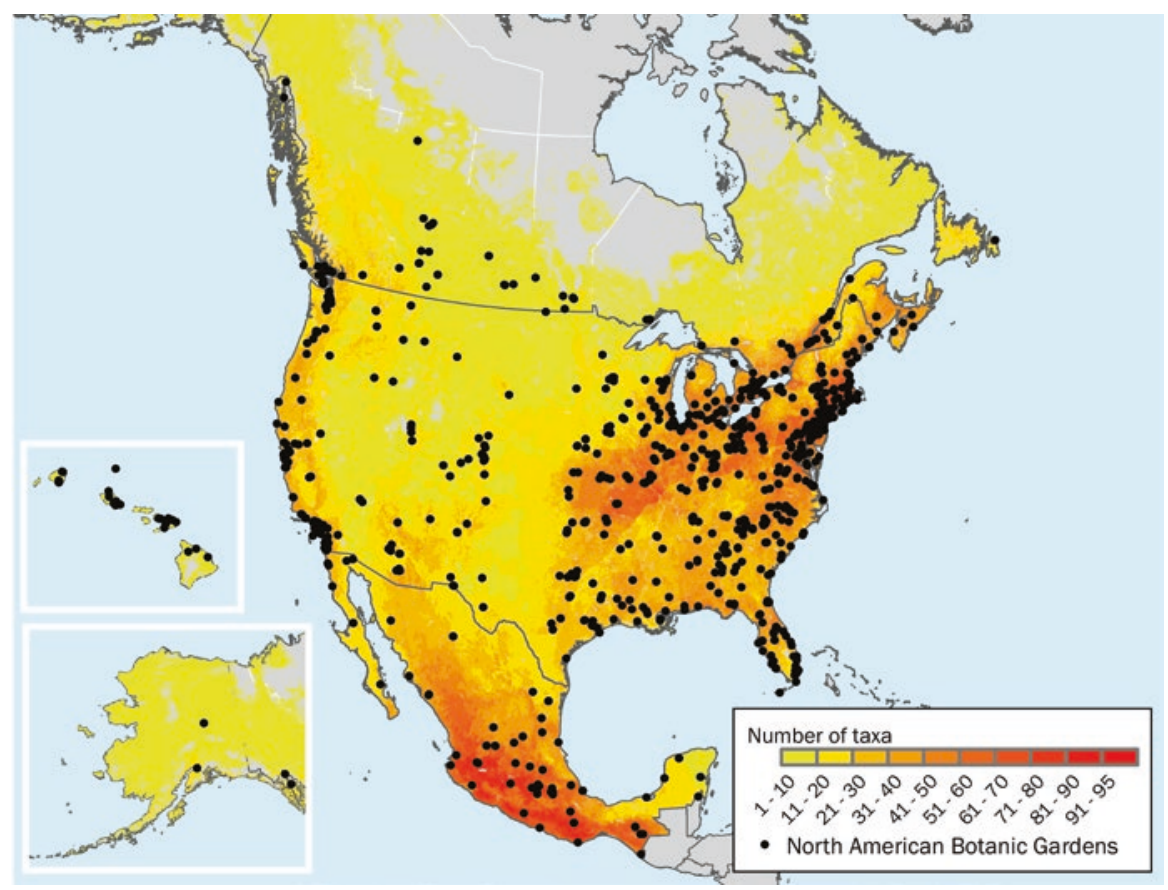

Fig. 12.1 Widespread distribution of 1037 botanical gardens in North America against a heat map of taxonomic richness of CWR (Greene et al. 2018). (Data from PlantSearch database (BGCI 2017b)) 


\subsection{Planning and Partnering for Public Education and Outreach}

\subsubsection{Human Behavior, Developing Capacity, and Educational Programming}

Education and outreach programs on CWR should be designed to increase the knowledge and capacity of diverse stakeholders to participate in conservation, exploration, and use, as well to increase general awareness of the subject. Audience members may be at different starting places in their understanding of biodiversity, plant conservation, agriculture, and food. Therefore, adaptable education strategies are required. While there are many different methods for public engagement in the sciences, we have outlined an adapted process combining capacity building (Hunter and Heywood 2011) and public engagement (Varner 2014) as a potential model for executing CWR education and outreach. Figure 12.2 portrays an evidence-based model for capacity building and education divided into three iterative phases: (1) development and planning, (2) implementation and action, and (3) evaluation and amplification. Development and planning involves defining goals, stakeholders, and audience while also identifying collaborators and assessing capacity assets and needs. Implementation and action involves dynamic activities (recognizing that educational scholarship has proven that dynamic approaches, such as experiential learning, are among the most effective) and formative assessment (i.e., adaptively considering the educational strategy during its execution). At this stage, reflection and feedback are very important and can be used to determine if different types of educational or training approaches can increase learning. The evaluation and

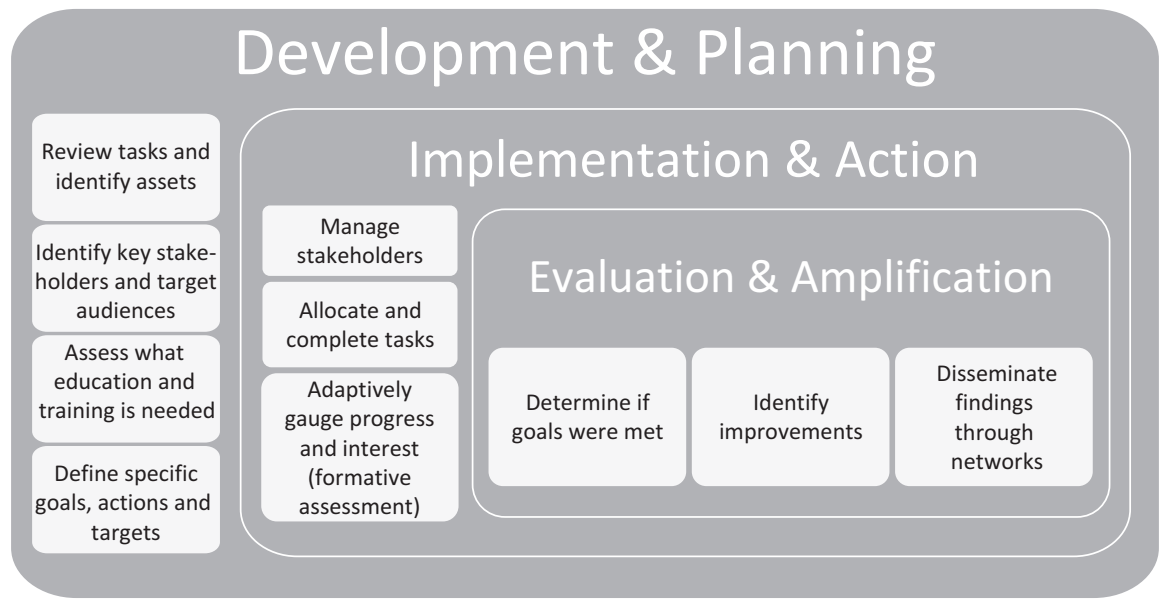

Fig. 12.2 A CWR capacity building and public engagement process. (Adapted from Varner (2014) and Hunter and Heywood (2011)) 
amplification phase involves evaluation, reflection, and dissemination of education and outreach results. Armed with a basic understanding of processes for public engagement, CWR researchers can design effective programs for engaging the public in their research areas.

Human behavior lies at the core of outreach, education, and conservation (Amel et al. 2017), and our evolving understanding of human behavior should be leveraged to meet outreach and education goals. Understanding drivers that impact behavior can help frame messages and create effective capacity development and educational programs (Sparkman and Walton 2017). Public engagement is impacted by factors such as personal values, attitudes, and beliefs (Schultz et al. 1995; Crompton 2010). High-impact environmentally responsible behaviors (e.g., car-free living and reduced flying) are often more difficult to change than lowimpact behaviors (e.g., recycling) (Stern et al. 1999; Steg and Vlek 2009; Gifford et al. 2011). Examining factors that influence behavioral change reveals interesting insight into the power of communication and messaging. Subtle changes in messaging can have significant impacts. For example, people were twice as likely to order meatless meals when signage indicated that people were already changing their habits (now eating less meat) compared to signage that says that people are attempting to change their habits (trying to eat less meat) (Sparkman and Walton 2017). Human behavior in relation to natural resources and informal education is both well-developed, and daunting, areas of scholarship. When designing informal education programs, the researcher should seek to follow the most current knowledge on educational efficacy but will need to right size the level of background scholarship brought to bear in order to keep educational design tractable. As the intended outreach strategy increases in complexity, it will make increasing sense to partner with education and outreach specialists to maximize audience identification, targeting, and engagement, as well as to think though specific aspects of capacity building.

\subsubsection{Educational Allies: Identifying Stakeholders Across Disciplines}

A wide world of expertise in informal education and community outreach exists, often with allied scientific focus. Leveraging previous work and building effective partnerships for education and outreach can be approached in many ways depending on the capacity of the organization and the stakeholders it serves. There are no hard and fast rules for exactly who should be included as a stakeholder. However, it has been shown that creating a culture of inclusivity is essential to building equitable community food systems (Clark et al. 2017). This means welcoming people of all racial, religious, and ethnic backgrounds (especially indigenous communities who often carry the ethnobotanical knowledge of CWR), disabilities, age, sexual orientations, and gender identities. It is also important to include stakeholders from 
diverse political, professional, and other special interest lines. This is especially relevant in communication strategies when it comes time to hone specific messages to specific groups, as various audience subgroup attributes may necessitate unique communication tactics. Hunter and Heywood (2011) outline the following list of 13 potential CWR stakeholder groups to consider:

- Senior policy-makers and political leaders

- Biodiversity, environment, and agriculture senior decision-makers

- Leadership at relevant organizations and institutes

- Planners from local, regional, and national levels

- Scientists and researchers

- Managers of protected areas

- Project management staff

- Field technicians

- University faculty, staff, and students

- Communications and public awareness specialists

- Extension and outreach specialists

- Information analysts and managers

- Community leaders and organizations

For North American scientists working on CWR, there are a number of educational allies that have engaged around the topic and have familiarity and resources that could be used and adapted. Specifically, the Crop Science Society of America, American Society of Agronomy, Botanical Society of America, American Public Gardens Association, American Society for Plant Biology, Canadian Botanical Association, Canadian Society of Agronomy, and Mexican Association of Botanic Gardens (Asociación Mexicana de Jardines Botánicos), as well as the CGIAR network including the International Maize and Wheat Improvement Center (CIMMYT) in Mexico. In addition, the federal programs responsible for biodiversity and germplasm resources are key allies as well: La Comisión Nacional para el Conocimiento y Uso de la Biodiversidad (CONABIO) in Mexico, the US Department of Agriculture Agricultural Research Service (USDA ARS) in the USA, and both the Plant Gene Resources of Canada (PGRC) and BiodivCanada in Canada. There are also several international allies integrating CWR outreach with research programs. The largest international players in bridging the gap between CWR research and public outreach are the Millennium Seed Bank (MSB) at the Royal Botanic Gardens, Kew in Great Britain, and the Crop Trust in Bonn, Germany, who work cooperatively. The Crop Trust is intimately involved in the management of the Svalbard Global Seed Vault in Norway, and the Crop Trust's website contains a wealth of resources to relate CWR to the public (Crop Trust 2017). The Svalbard Global Seed Vault in particular has captured public attention with major media outlets at regional, national, and international levels all covering it with relatively high frequency. Quite recently, there was a front page article in The New York Times titled, "Safeguarding Seeds That May Feed the Future," about efforts to conserve agricultural diversity at the International Center for Agricultural Research in Dry Areas (ICARDA), which 
connected global geopolitics through the CGIAR system to Svalbard (Sengupta 2017). Additionally, international organizations such as Botanic Garden Conservation International and Bioversity International have produced excellent communications resources on CWR (BGCI 2017a; Bioversity International 2017).

Educational organizations such as the North American Association for Environmental Education, 4H, Girl Guides, Boy Scouts, Youth and United Nations Global Alliance (YUNGA), and Future Farmers of America could provide support and resources to educators who are interested in topics aligned to CWR. Agricultural extension services, which are present in many countries and active in North America, have significant knowledge of informal education and are often institutionally collocated with germplasm researchers. Additionally, organizations dedicated to the wide dissemination of applied biological science work, such as museums, botanic gardens, food and environmental activist groups, related NGOs, and even communications platforms such as TED Talks and the journalistic media, all represent potential CWR allies. In the journalism world, the excellent writing and photography by National Geographic related to food (e.g., the Where Food Began issue in 2008) have had tremendous public awareness impact (Mann 2008).

Environmental NGOs (ENGOs), such as the Nature Conservancy, David Suzuki Foundation, World Wildlife Fund, and many others, are involved in research, education, and outreach across North America and would be natural partners in CWR education. Regional issues and local level solutions are often raised by ENGOs with significant networks, programs, and memberships. Food policy councils (FPCs) are an important network in the USA and Canada with over 300 active councils in 2016 (Sussman and Bassarab 2016). These councils (also called food policy coalitions, collaboratives, or networks) broadly aim to support effective food policy and tend to have varying mandates and relationship/connections with different levels of government (local, regional, state/provincial, and federal). Since 2007, the number of councils in Canada and the USA has been steadily rising. This growth in food policy councils is thought to be a community response to increasing recognition of the potential role of government in addressing food system challenges, as well as the interest by food policy stakeholders to work collectively across jurisdictions and organizations (Sussman and Bassarab 2016). Many food policy councils support educational initiatives and could be important networks for raising awareness of CWR research.

We can also look to successful science outreach campaigns in North America for inspiration. The pollinator community has engaged in public outreach quite masterfully, especially since the large-scale reporting on honey bee colony collapse disorder (CCD) began in 2006. Capitalizing on this public attention, various outreach organizations related to pollinators have been successful in first educating the public that while CCD is an issue specifically of honeybees (Apis mellifera L.), it is but a canary in the coal mine with regard to threats across the species that provide pollinator services. These public information campaigns have been wisely linked to agriculture, both in terms of the necessity of pollinators to many crop production systems and the challenges that agriculture represents for pollinators in peril. In 
particular, the Million Pollinator Garden Challenge, a collaboration of many activist, science, and public engagement institutions, presents a wonderful example of a continental effort to mobilize the general public for active conservation activities and education (National Pollinator Garden Network 2017). As with CWR, an important hook of the Million Pollinator Garden Challenge is the direct link between their subject matter (pollinators) and the provisioning of food through agriculture. People certainly care about food, and with well-chosen partnerships and an eye for a dynamic learning platform, there is no reason why CWR-related groups couldn't be just as successful at capturing the public imagination as counterparts in the pollinator community.

The pollinator example is also illustrative of the successful use of citizen science, which is an excellent option for high-impact, dynamic outreach which also involves public participation in the scientific process. Citizen science has become a valuable resource for global change science, although it is still considered to be underutilized (Theobald et al. 2015). Citizens contribute to generating new scientific knowledge and understanding while simultaneously democratizing the research process. Programs take many different forms and can involve many activities, such as education, sharing of best practices, building capacity and understanding of the scientific process, and research initiatives. Public participation in research initiatives could include CWR identification, collection, conservation, planting, celebration, and advocacy. The voluntary public role in citizen science depends on many factors such as the scientific topic of study, audience, program goals and mission, and spatial and temporal ranges.

\subsubsection{Partnering for Outreach: Leveraging Strengths}

The most salient challenges of public outreach for the CWR research community are the lack of access to target audiences and the lack of expertise in informal educational content delivery. While all researchers would benefit from at least a cursory understanding of their intended audiences and methods of effective informal education, it is most efficient to partner with organizations and individuals specializing in these skills to deliver quality outreach. The universe of qualified and active outreach partners for CWR-related projects is immense, and it can be daunting to establish new relationships across disciplines. Tips for considering partnerships that will be mutually beneficial to all partners highlight the need to evaluate the potential for accountability, rapport, communication and understanding, realism, voice, and sustainability (Davidson and Clark 2017). Keeping these attributes in mind will help researchers identify the most fitting partners for outreach. For university-affiliated researchers, the university may have an office of public engagement and outreach that can help. In addition, faculties of communication, education, and psychology may have scholars of informal education and learning who can help to identify partners. It is also important to realize that most communities have nonprofit institutions 
specializing in informal education in the biological and environmental sciences that can be key points of entry into the professional world of science engagement. These include science museums, botanic gardens, and nature centers. Many scientific professional organizations also have public engagement and education staff.

\subsection{Botanical Gardens for CWR Education}

Botanical gardens are living museums of plants and are important nodes of CWR research, outreach, and collaboration. These gardens are located in virtually every major population center in North America. The American Public Gardens Association includes approximately 600 member institutions throughout North America, many of them botanic gardens or public gardens with science education programming. These gardens collectively welcome tens of millions of visitors annually who can benefit from the experience of learning about plants. Recent research on the geographic distribution of CWR has been built from herbarium specimens, which are overwhelmingly housed within botanic gardens where plant taxonomists assiduously describe and catalogue the diversity of plants on earth (Castañeda-Álvarez et al. 2016). As such, botanic gardens are vital learning centers about plants located among key outreach constituencies that already have strong fluency in topics related to food and agriculture.

Botanic gardens are often defined by the plants that comprise their living collections. As gardens have sought to provide greater value and relevance to society in recent decades, some have focused their collection activities on crops and CWR, even incorporating breeding programs. For example, the National Tropical Botanical Gardens in Hawaii houses the world's foremost collection of cultivated and wild breadfruit (Artocarpus J. R. Forst. \& G. Forst. spp.) (Ragone 2007). The Minnesota Landscape Arboretum houses an impressive collection of fruit cultivars and relatives (Malus Mill., Prunus L., and Vitis L.) associated with its widely known breeding program (Hockenberry Meyer et al. 2010). Such gardens, in particular, are very familiar with CWR and are already engaging a general audience in outreach related to both familiar crops and their wild cousins. These institutions are excellent prospective partners both in outreach and basic CWR research.

Most public gardens see informal education as central to their mission. They often include within their staff professionals who are experts at delivering informal education to a variety of audiences and have a deep understanding of their particular community's interest in various plant-related topics. Furthermore, many public gardens are adept at both the design and subsequent evaluation of informal education activities. Recently, there have been calls from within the botanical community for gardens to engage even more deeply with agriculture and with CWR in particular (Miller et al. 2015). For example, the American Public Gardens Association recently launched a Food and Agriculture Professional Section with the specific goal to advance CWR research and outreach in North America (APGA 2017). 
Like other cultural learning centers such as museums, botanic gardens create exhibits using a variety of media to relate plants to people. A major strength of botanic gardens relative to other museums is that gardens have professional horticultural staff members who can facilitate the incorporation of living plant materials into their exhibits. Many gardens are already expanding their exhibit offerings into the realm of crop and even CWR education. For example, the Louisiana State University AgCenter Botanic Gardens, which is one of many gardens associated with an agricultural university in North America, has created an exhibit titled "Corn Through the Ages," which seeks to demonstrate the history of human improvement of Zea mays L. from teosinte all the way through modern hybrids and genetically modified organisms (GMOs) (J. Khuehny, personal communication). The US Botanic Garden in Washington, D.C., created the exhibit "Amber Waves of Grain," which demonstrated the breeding history of wheat (Fig. 12.3), and included wheat progenitors such as einkorn, emmer, and spelt, as well as new crops such as Kernza ${ }^{\circledR}$, which was derived from Thinopyrum intermedium (Host) Barkworth \& D. R. Dewey, a CWR of wheat (Novy 2016). The Missouri Botanical Garden in St. Louis created an exhibit of its North American Vitis (grape) collection, which include CWR important as rootstocks to the commercial viticulture industry (Miller et al. 2015).

Many botanical gardens in North America are involved in food-related activities such as garden displays and exhibits, classes and lectures, training programs, and

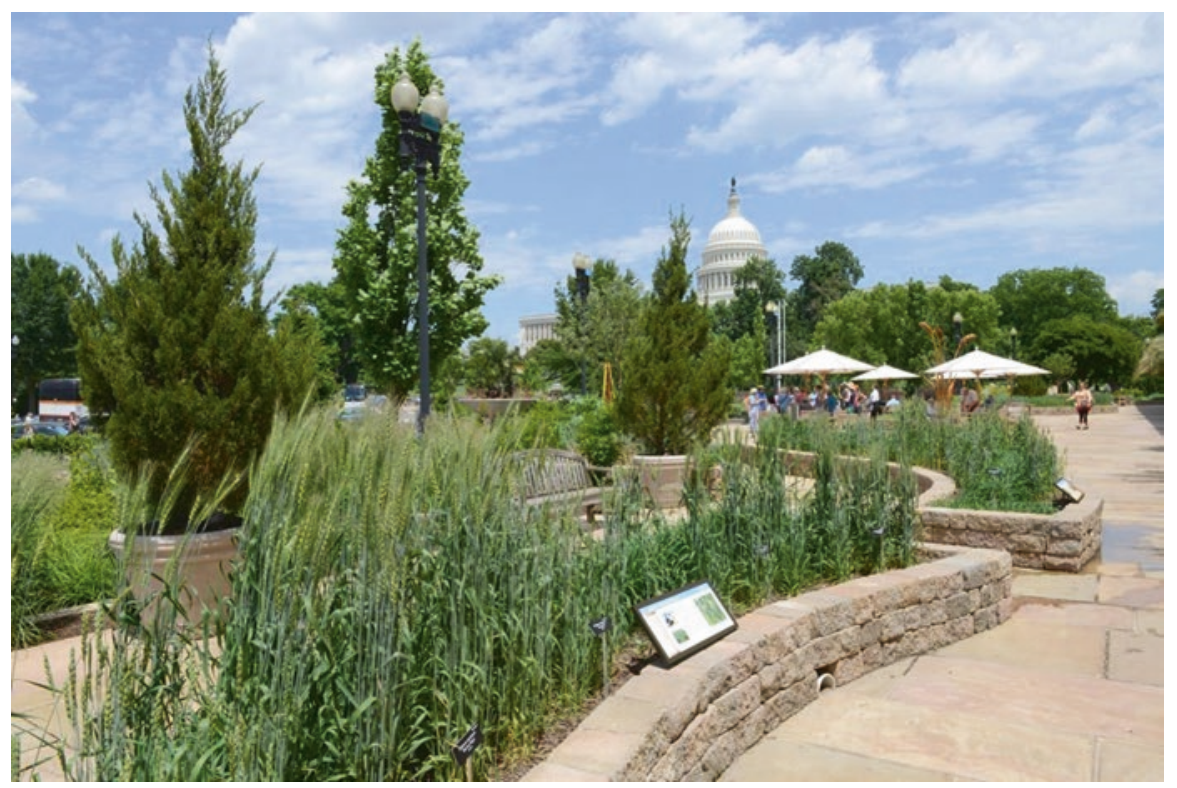

Fig. 12.3 Wheat breeding exhibit at the US Botanic Garden engaging the public on the wonders of wheat breeding. (Photo courtesy of the US Botanic Garden) 
production-based farms (Kinley 2017). At the University of British Columbia Botanical Garden (UBC-BG), the Food Garden is an important display and educational hub. The site features an outdoor classroom and new interpretive signs (including one on CWR) and is a key location used in the Sustainable Communities Field School targeting team-building activities for local businesses (Figs. 12.4 and 12.5). In addition to annual and perennial food plants, the area is also used to grow indigenous food plants such as camas (Camassia quamash (Pursh) Greene), wild

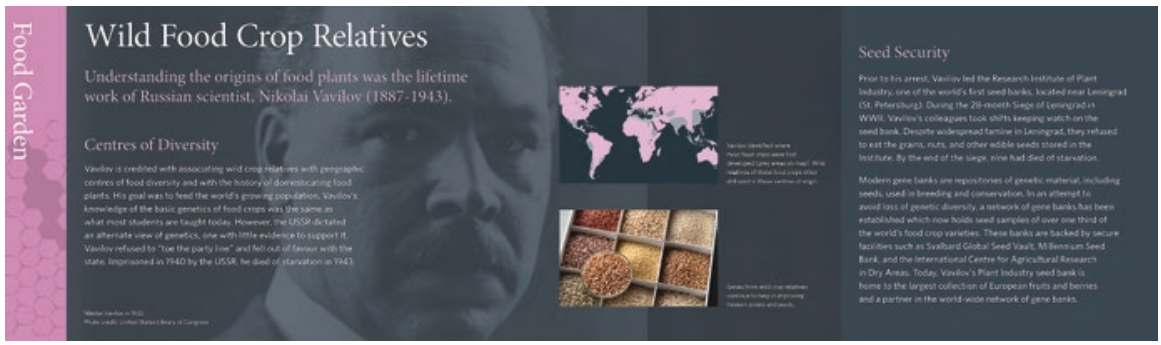

Fig. 12.4 Example of crop wild relative interpretive sign developed for display at the University of British Columbia Botanical Garden. (Photo courtesy UBC Botanical Garden)

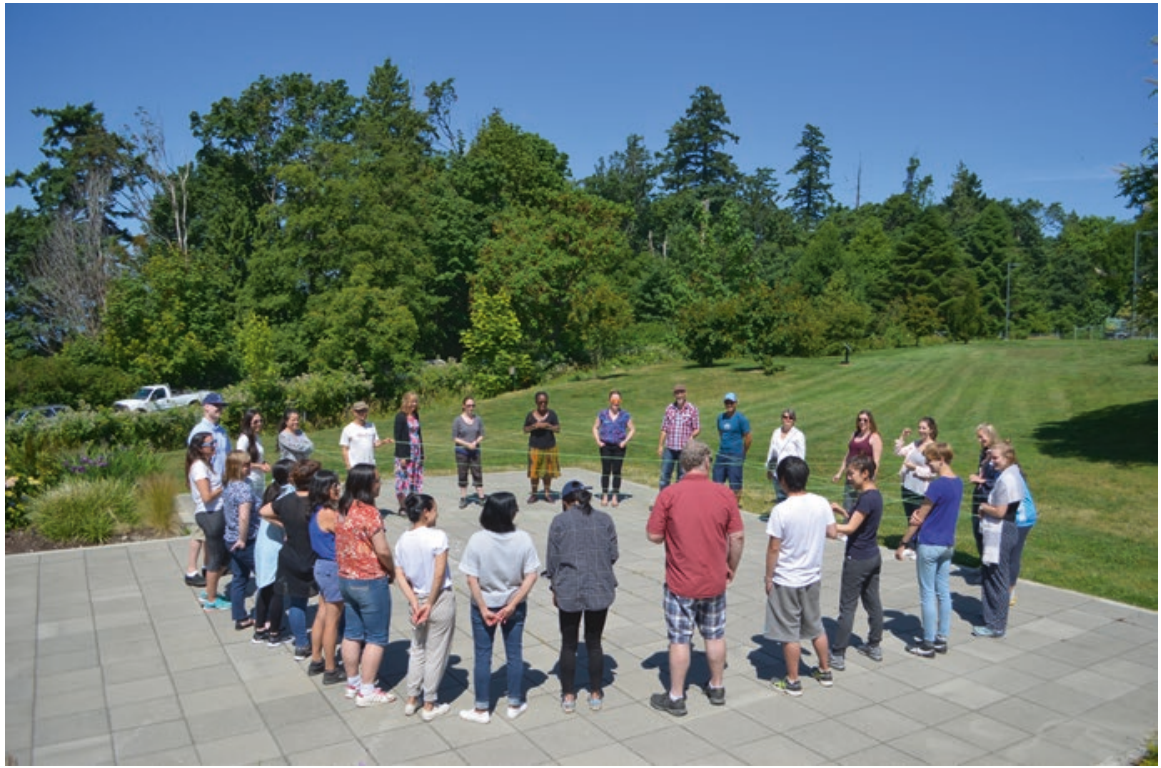

Fig. 12.5 Closing activity at UBC Botanical Garden Field School where business teams reflect on their time learning about sustainable food systems, local biodiversity, water conservation, and waste cycling in nature. (Photo courtesy UBC Botanical Garden) 
strawberry (Fragaria virginiana Mill.), and nodding onion (Allium cernuum Roth). Inspired by the espalier apple collection within the Food Garden, the annual UBC Apple Festival hosts over 10,000 people during the two-day event and sells 35,000 pounds of local apples featuring over 60 different varieties. Similarly, the Fairchild Tropical Botanic Garden in Miami celebrates its mango collection with their International Mango Festival.

Since botanic and other public gardens are already present in virtually every major population center in North America (Fig. 12.1) and have the horticultural and educational skills for excellent plant-based public education and outreach, they should be high on the list of potential collaborators for CWR outreach programs.

\subsection{Future Outlook}

CWR are vital genetic resources with great economic and cultural importance. Efforts to integrate public education and outreach with CWR research programs will galvanize the public's understanding of the imperative to explore, conserve, and use CWR. Drawing from psychology and climate change education research, we learn that environmental values expressed from the public can lead to legislative and infrastructural changes which in turn can reinforce additional public environmental attitudes (Tibbs 2011), which is ultimately required to achieve the public investments needed to execute robust CWR research programs. Ideally, as CWR programs continue to advance in North America, they will be accompanied by an integrated and broad effort to educate multiple segments of the public, with special emphasis on key stakeholders and decision-makers, about the societal relevance of conserving and utilizing CWR.

There is no time like the present to act. The public is indeed fascinated with the science and systems underpinning our food. There is a general sense of urgency around biodiversity conservation in general and certainly around conservation efforts integral to human well-being. Finally, research in North American crop wild relatives is active and increasing. This confluence of public interest and advancing research presents the perfect context and timing for a major public outreach and education campaign. The North American CWR community should to take advantage of this positive opportunity.

\section{References}

Amel E, Manning C, Scott B, Koger S (2017) Beyond the roots of human inaction: fostering collective effort toward ecosystem conservation. Science 356(6335):275-279

Andrews E et al (2005) Scientists and public outreach: participation, motivations, and impediments. J Geosci Educ 53(3):281-293

APGA (American Public Gardens Association) (2017) Why join a professional section? https:// publicgardens.org/professional-development/why-join-professional-section. Accessed 5 Dec 2017 
BGCI (Botanic Garden Conservation International) (2017a) Communication tools to promote crop wild eelatives. http://www.bgci.org/worldwide/CWR_communication/. Accessed 29 Nov 2017

BGCI (Botanic Garden Conservation International) (2017b) PlantSearch. https://www.bgci.org/ plant_search.php. Accessed 29 Nov 2017

Bioversity International (2017) Crop wild relatives. https://www.bioversityinternational.org/cwr/. Accessed 29 Nov 2017

Boyer EL (1996) The scholarship of engagement. J Public Ser Outreach 1(1):11-20

Castañeda-Álvarez NP et al (2016) Global conservation priorities for crop wild relatives. Nat Plants 2(4): 16022

Ceballos $\mathrm{G}$ et al (2015) Accelerated modern human-induced species losses: entering the sixth mass extinction. Sci Adv 1(5):e1400253

Clark JK et al (2017) Fail to include, plan to exclude: reflections on local governments' readiness for building equitable community food systems. Built Environ 43(3):315-327

Convention on Biological Diversity (2012) Global Strategy for Plant Conservation: 2011-2020. Botanic Garden Conservation International, Richmond, UK

Crompton T (2010) Common cause: the case for working with our cultural values. WWF UK

Crop Trust (2017) Crop wild relatives. https://www.croptrust.org/our-work/supporting-crop-conservation/crop-wild-relatives/. Accessed 29 Nov 2017

Davidson G, Clark JK (2017) Tips for fruitful community-university partnerships and research. Ohio State University. https://assets.jhsph.edu/clf/mod_clfResource/doc/Community-University \%20Relationships.pdf. Accessed 29 June 2018

Gifford R, Kormos C, McIntyre A (2011) Behavioral dimensions of climate change: drivers, responses, barriers, and interventions. Wiley Interdiscip Rev Clim Chang 2(6):801-827

Greene SL, Khoury CK, Williams W (2018) Wild plant genetic resources in North America: an overview. In: Greene SL, Williams KA, Khoury CK, Kantar MB, Marek LF (eds) North American crop wild relatives: conservation and use. Springer in press

Hockenberry Meyer M et al (2010) Public gardens: fulfilling the university's research mission. Hort Technology 20(3):522-527

Hunter D, Heywood V (2011) Crop wild relatives: a manual of in situ conservation. Earthscan https://www.bioversityinternational.org/fileadmin/user_upload/online_library/publications/ pdfs/1487.pdf. Accessed 5 Dec 2017

Kinley EL (2017) An evaluation of food systems education and interpretation in U.S. public gardens. Masters Thesis, University of Delaware

Mann CC (2008) Where food begins. National Geographic Magazine. http://ngm.nationalgeographic.com/2008/09/table-of-contents. Accessed 5 Dec 2017

Miller AJ et al (2015) Expanding the role of botanical gardens in the future of food. Nature Plants. Article Number 15078

National Pollinator Garden Network (2017) Million Pollinator Garden Challenge. http://millionpollinatorgardens.org/. Accessed 5 Dec 2017

Novy A (2016) Botanic garden profile: the united states botanic garden in washington, DC. Sibbaldia 14:15-35

Ragone D (2007) Breadfruit: Diversity, conservation and potential. https://www.actahort.org/ books/757/757_1.htm. Accessed 29 June 2018

Royal Botanic Gardens Kew (2016) State of the World's Plants report - 2016. Royal Botanic Garens, Kew

Schultz PW, Oskamp S, Mainieri T (1995) Who recycles and when? A review of personal and situational factors. J Environ Psychol 16:106-121

Sengupta S (2017) How a Seed Bank, almost lost in Syria's war, could help feed a warming planet. The New York Times. https://www.nytimes.com/2017/10/13/climate/syria-seed-bank. html. Accessed 5 Dec 2017

Sparkman G, Walton GM (2017) Dynamic norms promote sustainable behavior, even if it is counternormative. Psychol Sci 28(11):1663-1674 
Steg L, Vlek C (2009) Encouraging pro-environmental behaviour: an integrative review and research agenda. J Environ Psychol 29(3):309-317

Stern PC et al (1999) A value-belief-norm theory of support for social movements: the case of environmentalism. Human Ecol Rev 6(2):81-97

Sussman L, Bassarab K (2016) Food policy council report 2016. https://assets.jhsph.edu/clf/mod_ clfResource/doc/FPC\%20Report\%202016_Final.pdf. Accessed 5 Dec 2017

Theobald EJ et al (2015) Global change and local solutions: tapping the unrealized potential of citizen science for biodiversity research. Biol Conserv 181:236-244

Tibbs H (2011) Changing cultural values and the transition to sustainability. J Futures Stud $15(3): 13-32$

United Nations (2017) Sustainable development goals. http://www.un.org/sustainabledevelopment/sustainable-development-goals/. Accessed 5 Dec 2017

Varner J (2014) Scientific outreach: toward effective public engagement with biological science. Bioscience 64(4):333-340

Open Access This chapter is licensed under the terms of the Creative Commons Attribution 4.0 International License (http://creativecommons.org/licenses/by/4.0/), which permits use, sharing, adaptation, distribution and reproduction in any medium or format, as long as you give appropriate credit to the original author(s) and the source, provide a link to the Creative Commons license and indicate if changes were made.

The images or other third party material in this chapter are included in the chapter's Creative Commons license, unless indicated otherwise in a credit line to the material. If material is not included in the chapter's Creative Commons license and your intended use is not permitted by statutory regulation or exceeds the permitted use, you will need to obtain permission directly from the copyright holder. 